\title{
Relationship between the equatorial electrojet and global Sq currents at the dip equator region
}

\author{
Nurul Shazana Abdul Hamid ${ }^{1,2^{*}}$, Huixin Liu ${ }^{1,3^{*}}$, Teiji Uozumi ${ }^{3}$, Kiyohumi Yumoto ${ }^{1,3}$, Bhaskara Veenadhari ${ }^{4}$, \\ Akimasa Yoshikawa ${ }^{1,3}$ and Jairo Avendaño Sanchez ${ }^{5}$
}

\begin{abstract}
The equatorial electrojet (EEJ) is a strong eastward ionospheric current flowing in a narrow band along the dip equator. In this study, we examined the EEJ-Sq relationship by using observations at six stations in the South American, Indian, and Southeast Asian sectors. The analysis was carried out with data on geomagnetically quiet days with $K p \leq 3$ from 2005 to 2011. A normalization approach was used because it yields more accurate results by overcoming the uncertainties due to latitudinal variation of the EEJ and Sq. A weak positive correlation between the EEJ and Sq was obtained in the Southeast Asian sector, while weak negative correlations were obtained in the South American and Indian sectors. EEJ-Sq relationship is found to be independent of the hemispheric configuration of stations used to calculate their magnetic perturbations, and it also only changed slightly during low and moderate solar activity levels. These results demonstrate that the Southeast Asian sector is indeed different from the Indian and South American sectors, which is indicative of unique physical processes particularly related to the electro-dynamo. Furthermore, we also demonstrate that the definition of the EEJ, that is, the total current or enhanced current, can significantly affect the conclusions drawn from EEJ-Sq correlations.
\end{abstract}

Keywords: H component; Equatorial electrojet; Sq current; Longitudinal dependence

\section{Introduction}

The horizontal magnetic field lines at the equator produce a unique current system like that described below. In the dayside equatorial ionosphere, currents driven by tidal wind through the dynamo mechanism cause an accumulation of charges, which are positive at dawn and negative at dusk terminators, and this results in an eastward electric field, $\underline{E}_{y}$, along the magnetic equator. The cross fields of this electric field and northward magnetic field results in an eastward Pedersen current and downward Hall current. The Pedersen current, $j_{-p}=\sigma_{1} \underline{E}_{y}$, flows dominantly at about $130-\mathrm{km}$ altitude in response to the peak Pedersen conductivity there. The downward Hall current leads to an accumulation of charges at the upper and lower edges of the dynamo layer, which results in the formation of an upward polarized electric field, $\underline{E}_{H}$, with a magnitude about 20 times larger than

\footnotetext{
* Correspondence: shazana.ukm@gmail.com; huixin@serc.kyushu-u.ac.jp ${ }^{1}$ Department of Earth and Planetary Sciences, Graduate School of Sciences, 33 Kyushu 4 University, 6-10-1 Hakozaki, Higashi-ku, Fukuoka 812-8581, Japan ${ }^{2}$ School of Applied Physics, Faculty of Science and Technology, Universiti Kebangsaan Malaysia, 43600 UKM, Bangi, Selangor, Malaysia Full list of author information is available at the end of the article
}

$\underline{E}_{y}$. This vertical polarization electric field induces a strong eastward Hall current, $j_{H}=\sigma_{2} \underline{B} \times \underline{E}_{H} / B$. This Hall current flows and peaks around 110-km altitude in response to the peak Hall conductivity there (Forbes, 1981; Onwumechili, 1992a; Prölss, 2004).

A rocket study by Onwumechili (1992b) has revealed the existence of an intense lower current layer and a weak upper current layer that peak at altitudes of $107 \pm$ $2 \mathrm{~km}$ and $136 \pm 8 \mathrm{~km}$, respectively. The eastward lower current layer, which consists mainly of a Hall current, is defined as the equatorial electrojet (EEJ), and it practically corresponds to $j_{-H}$. The upper current layer, which consists mainly of a Pedersen current, is thought to be part of the global Sq current and essentially corresponds to $j_{-p}$. The global Sq current system is characterized by dayside vortices that are counterclockwise in the northern hemisphere and clockwise in the southern hemisphere. Both currents overlap to give the total current at the dip equator: $j_{-T}=j_{-p}+j_{H}=\left(\frac{\sigma_{2}^{2}}{\sigma_{1}}+\sigma_{1}\right) \underline{E}_{y}=\sigma_{3} \underline{E}_{y}$, where $\sigma_{3}$ is the Cowling conductivity (Hirono, 1950, 1952) that perturbs the geomagnetic northward $(H)$ component of

\section{实}




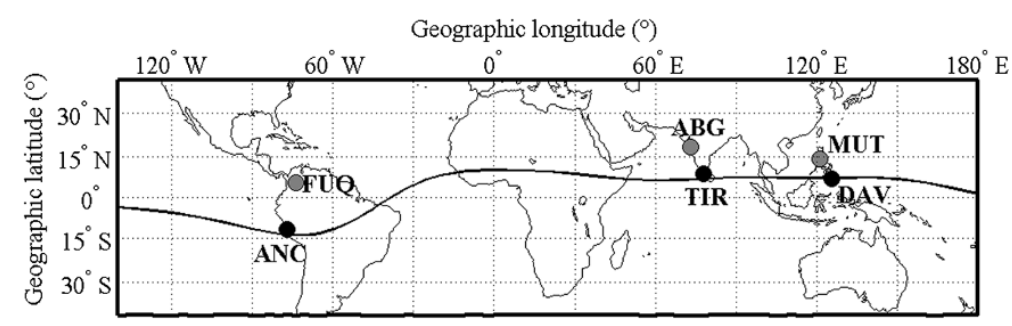

Figure 1 A map of stations used in this study.

equatorial ground magnetometer observations. Detailed studies of both currents can be found in Onwumechili (1992b); Stening (1995), and Onwumechili (1997).

The relationship between the EEJ and Sq current has been studied for many years, but until now, agreement still appears to be lacking on this topic. Some previous studies found a good correlation between them, while others have showed nonexistent or only weak correlations. This conflict likely results from the lack of good continuous data and the difficulty of isolating global Sq and EEJ at dip equator stations. Most studies have used the two-station method to calculate the EEJ as the difference between measurements taken at a dip equator station and at an off-dip equator station, and data from the off-dip equator station are typically used directly to represent the global Sq contribution at the dip equator. In many cases, no significant correlation is obtained as shown in Ogbuehi et al. (1967), Okeke et al. (1998), and Okeke and Hamano (2000). In contrast, studies by Kane (1971) and Yamazaki et al. (2010), which used the total $H$ component at the dip equator to represent the EEJ (which we hereafter refer to as the total current), revealed a good correlation with Sq at off-dip equator stations. This discrepancy might be understood by the insight that the correlation coefficient between two time series $x_{1}$ and $x_{1}+x_{2}$ will usually be different from that between $x_{1}$ and $x_{2}$ (Mann and Schlapp, 1988).

One also needs to keep in mind that the EEJ current varies drastically with latitude, especially within $\pm 6^{\circ}$ across the dip equator. This fact introduces some uncertainty in the EEJ estimation from ground-based data as it is often impossible to locate the station exactly at the dip latitude. So far, this problem was encountered by all previous researchers on this topic. Furthermore, the Sq current at the dip equator also differs from the one outside this region as the Sq current is also known to vary with latitude. Most previous studies directly used the Sq measured at off dipequator stations, and this will certainly affect the study of the EEJ-Sq relationship at the dip equator.

In the present study, we reexamined the EEJ-Sq relationship by using long-term ground-based magnetometer data simultaneously from station pairs in three longitude sectors. Furthermore, to overcome the above-mentioned uncertainties due to the latitudinal variation of EEJ and $\mathrm{Sq}$, we normalized the observation data to the dip equator using the CM4 model by estimating peak EEJ and Sq values at the dip equator to yield more accurate results. Additionally, we compared the EEJ-Sq relationship with the total current-Sq relationship. Possible mechanisms are then discussed to explain the results obtained.

\section{Data description and method of analysis}

We used ground magnetometer measurements from six stations in this study and Figure 1 shows the geographic distribution of these stations. The stations were grouped into three pairs, one in the South American sector, one in the Indian sector, and one in the Southeast Asian sector. Each pair consists of one station close to the dip equator and one station at an off-dip equator location. The station pairs were within the same longitude. Table 1 gives the coordinates of all stations. The time periods used for the data in this study are from 2005 to 2011.

Table 1 Geographic and geomagnetic coordinates of the stations used

\begin{tabular}{|c|c|c|c|c|c|c|}
\hline \multirow[t]{2}{*}{ Sector } & \multicolumn{2}{|l|}{ Station } & \multicolumn{2}{|l|}{ Geographic } & \multicolumn{2}{|c|}{ Geomagnetic } \\
\hline & Name & Code & Latitude $\left({ }^{\circ}\right)$ & Longitude $\left({ }^{\circ}\right)$ & Latitude $\left({ }^{\circ}\right)$ & Longitude $\left({ }^{\circ}\right)$ \\
\hline \multirow[t]{2}{*}{ South America } & Ancon & ANC & -11.77 & -77.15 & 0.77 & 354.33 \\
\hline & Fuquene & FUQ & 5.40 & -73.73 & 15.72 & 357.99 \\
\hline \multirow[t]{2}{*}{ India } & Tirunelveli & $\mathrm{TIR}$ & 8.7 & 77.80 & 0.21 & 149.30 \\
\hline & Alibag & $A B G$ & 18.62 & 72.87 & 10.36 & 146.54 \\
\hline \multirow[t]{2}{*}{ Southeast Asia } & Davao & DAV & 7.00 & 125.4 & -1.02 & 196.54 \\
\hline & Muntinlupa & MUT & 14.37 & 121.02 & 6.79 & 192.25 \\
\hline
\end{tabular}


For this study, we used the EUEL index (Yumoto and the MAGDAS Group, 2007; Uozumi et al. 2008). The hourly EUEL index was obtained from the $H$ component at all stations. In the construction of this index, the median value of the $H$ component was first subtracted from the original magnetic data to obtain $E R_{S}$ for each available equatorial station, $S$. The average value of $E R_{S}$ observed at the nightside (LT $=18-06)$ stations along the magnetic equatorial region gives the equatorial disturbance storm time index, EDst. This index represents global magnetic variation including disturbances in the equatorial region, particularly those from sudden storm commencement (SSC) and ring currents, and part of magnetospheric origin disturbances such as substorms and DP2 effects. The EUEL index used in this study is given by the subtraction of the EDst index from $E R_{S}$. More details on the EUEL index can also be found in Hamid et al. (2013). The analysis was carried out using the maximum EUEL index during noontime for days with $K p \leq 3$ during the years of 2005 to 2011. By taking data around noontime, we limited our analysis to the period when the EEJ current is strongest and avoided the morning and evening effects such as the counterelectrojet effect.

An ideal approach to isolate Sq and EEJ at the dip equator is to have a dense latitudinal chain of geomagnetic stations across the dip equator (Rigoti et al. 1999). In the lack of that, most previous studies assumed that the Sq current from the off-dip equator station was the same as the one at the dip equator station and directly subtracted it from equator data to obtain the EEJ (Rastogi et al. 2013) (see Figure 2a). However, since both the EEJ and $\mathrm{Sq}$ vary with latitude, there is significant uncertainty in such an approach. To minimize this uncertainty, we used the CM4 global current model (Sabaka et al. 2004) to normalize observation data to the dip equator. This method is similar to the one used in Manoj et al. (2006). Figure $2 \mathrm{~b}$ details an example from the TIR-ABG pair in

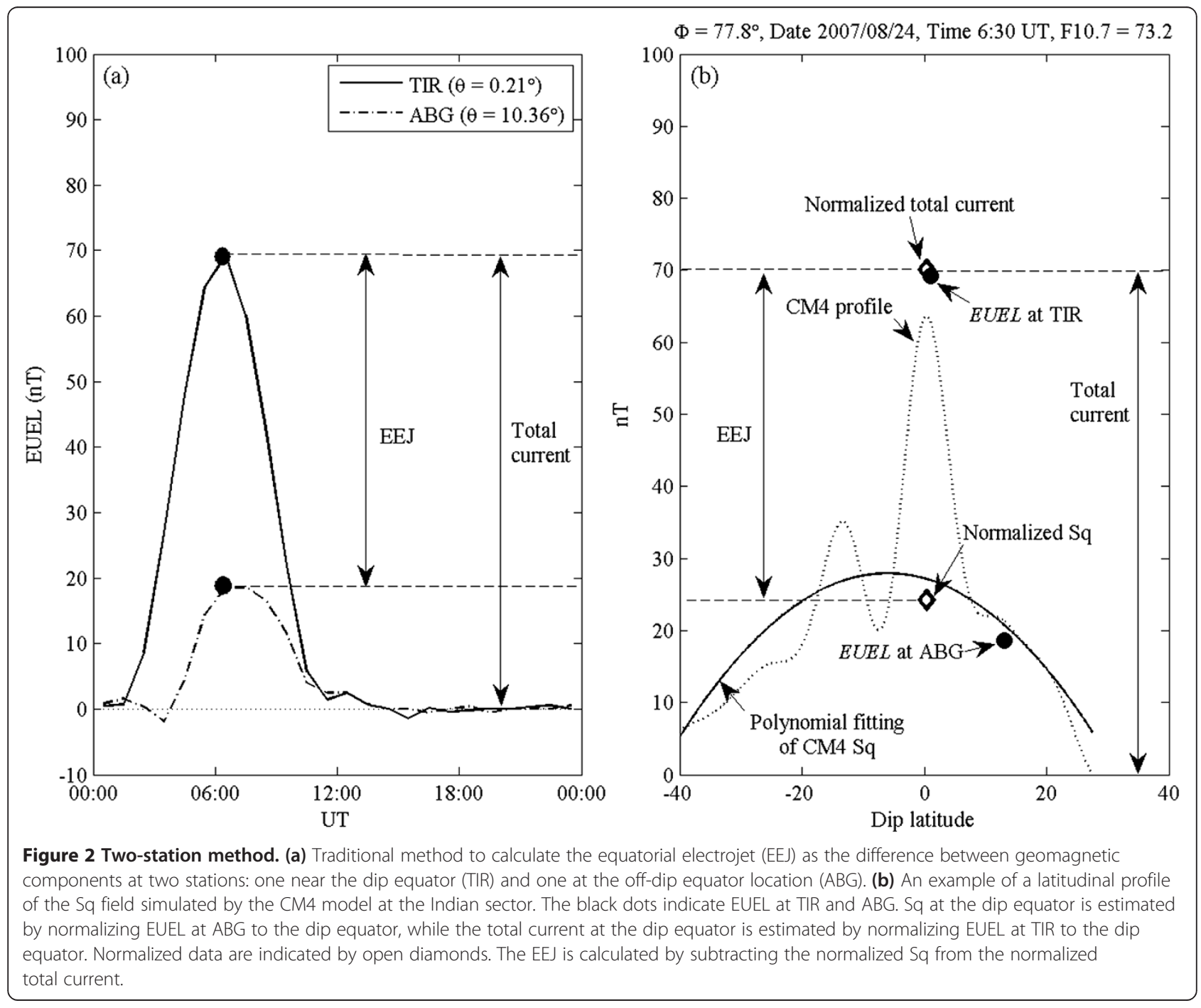


the Indian sector. Latitudinal profiles of Sq fields were obtained by fitting a polynomial of $2^{\circ}$ to the CM4 model after the region of $\pm 3^{\circ}$ at the dip equator was masked. The $6^{\circ}$ region across the dip equator was masked to avoid the influence of the CM4 EEJ signature. Using this latitudinal profile, we normalized the observed EUEL at the off-dip equator station $\left(\theta^{\circ}\right.$ dip latitude) to the dip equator $\left(0^{\circ} \mathrm{dip}\right.$ latitude) using the following formula:

$$
\operatorname{EUEL}\left(0^{\circ}\right)=\frac{\mathrm{CM}_{4}\left(0^{\circ}\right)}{\mathrm{CM}_{4}\left(\theta^{\circ}\right)} \operatorname{EUEL}\left(\theta^{\circ}\right)
$$

This gives the normalized Sq at the dip equator. Moreover, the EUEL observed at the station near the dip equator $\left(\theta^{\circ}\right.$ dip latitude) was normalized to the dip equator $\left(0^{\circ}\right.$ dip latitude) directly using the CM4 model profile and the same formula. This gives the normalized total current at the dip equator. In Figure 2b, the normalized data at the dip equator are indicated by the diamond symbol. The EEJ current was calculated as the difference between the normalized total current at the dip equator and the normalized Sq at the dip equator:

$$
\mathrm{EEJ}=\mathrm{EUEL}_{\mathrm{total}}\left(0^{\circ}\right)-\mathrm{EUEL}_{\mathrm{Sq}}\left(0^{\circ}\right)
$$

The same procedure was applied to all station pairs. Figure 3 shows the normalized EEJ and $\mathrm{Sq}$ at the dip equator calculated from all three station pairs from 2005 to 2011. Mostly, continuous data were obtained from the South American (ANC-FUQ pair) and Indian (TIRABG pair) sectors, but there were data gaps around the end of April to early September 2009 in the South American sector and from January to the end of April 2011 in the Indian sector. For the Southeast Asian sector (DAV-MUT pair), the plot of EEJ and normalized Sq had many data gaps including at the end of 2005, the end of 2006, a big gap from May 2008 to the middle of September 2009, and the first six months in 2010. These normalized EEJ and Sq were used in the following analysis.

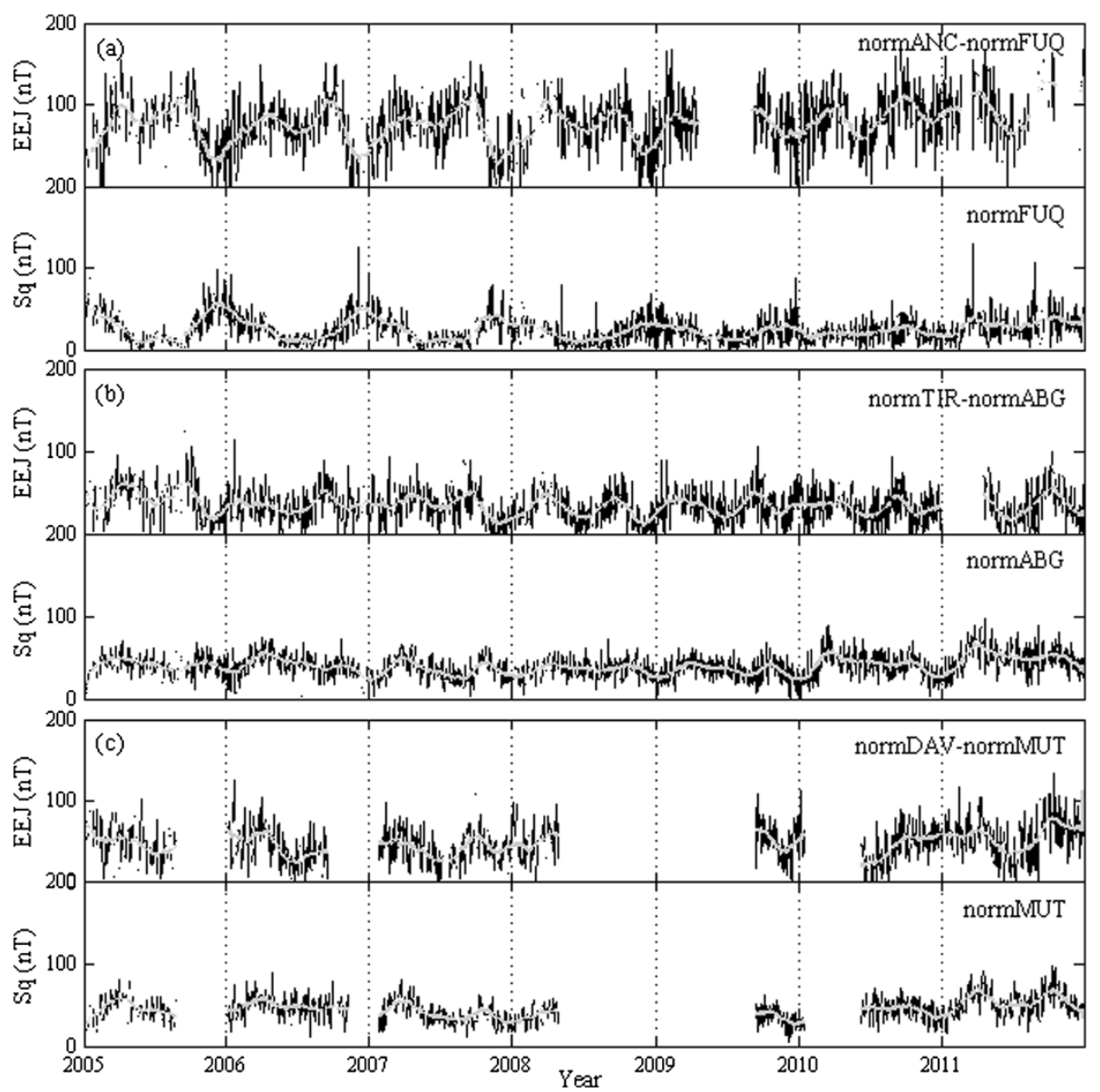

Figure 3 The EEJ and Sq calculated from three station pairs. (a) ANC and FUQ at South America, (b) TIR and ABG at India, and (c) DAV and MUT at Southeast Asia. Sq is given by the normalized EUEL from the off-dip equator station, while EEJ is calculated as the difference between the normalized total current and Sq at the dip equator. The gray lines indicate 27-day centered moving averages of the data. 
One can also see that EEJ varies with longitude, with the highest intensity in the South American sector followed by the Southeast Asian and Indian sectors. The monthly average of both EEJ and Sq for each year is presented in Figure 4. It is evident that EEJ was significantly larger than Sq in the South American sector, but both were comparable in the Indian and Southeast Asian sectors. Furthermore, double peaks were visible in the EEJ and prominent in the South American sector. Sq in the South American sector displayed annual variation with a minimum in June and maximum in December for the years 2005 to 2009. Little seasonal variation was observed in the other sectors.

\section{Relationship between the EEJ and Sq}

The top panels in Figure 5 show scatter plots of the EEJ against normalized $\mathrm{Sq}$ intensities measured at three station pairs for the whole study period. Box-fitting least squares (BLS) was applied and the corresponding linear regression and correlation coefficients are shown in this figure. The slope for the linear fitting was negative in the South American and Indian sectors but positive in the Southeast Asian sector. However, the scattering was quite large as can be seen in Figure 5. We therefore performed a $t$-test to examine the significance (with a confidence level of $95 \%$; $\alpha=0.05$ ) of both the slope, $\beta$, and the correlation coefficient, $R$. The null hypothesis was $H_{0}: \mathrm{A}=0$ (no significant relation and correlation), while the alternative hypothesis was $H_{1}: \mathrm{A} \neq 0$ (significant relation and correlation), where $\mathrm{A}$ in both hypotheses represents $\beta$ and $R$. We calculated the $t$ - and $p$-value to check whether we should reject $(p<\alpha)$ or accept $(p>\alpha)$ our null hypothesis. The statistic values obtained are shown in Table 2. The $p$-values were $<0.05$ for all $\beta$ and $R$ tested; thus, we reject the null hypothesis and conclude that at the $95 \%$ confidence level, both the $\beta$ and $R$ values obtained are significant. We therefore conclude that the EEJ and Sq at the dip equator are weakly correlated. The weak correlation was positive in the Southeast
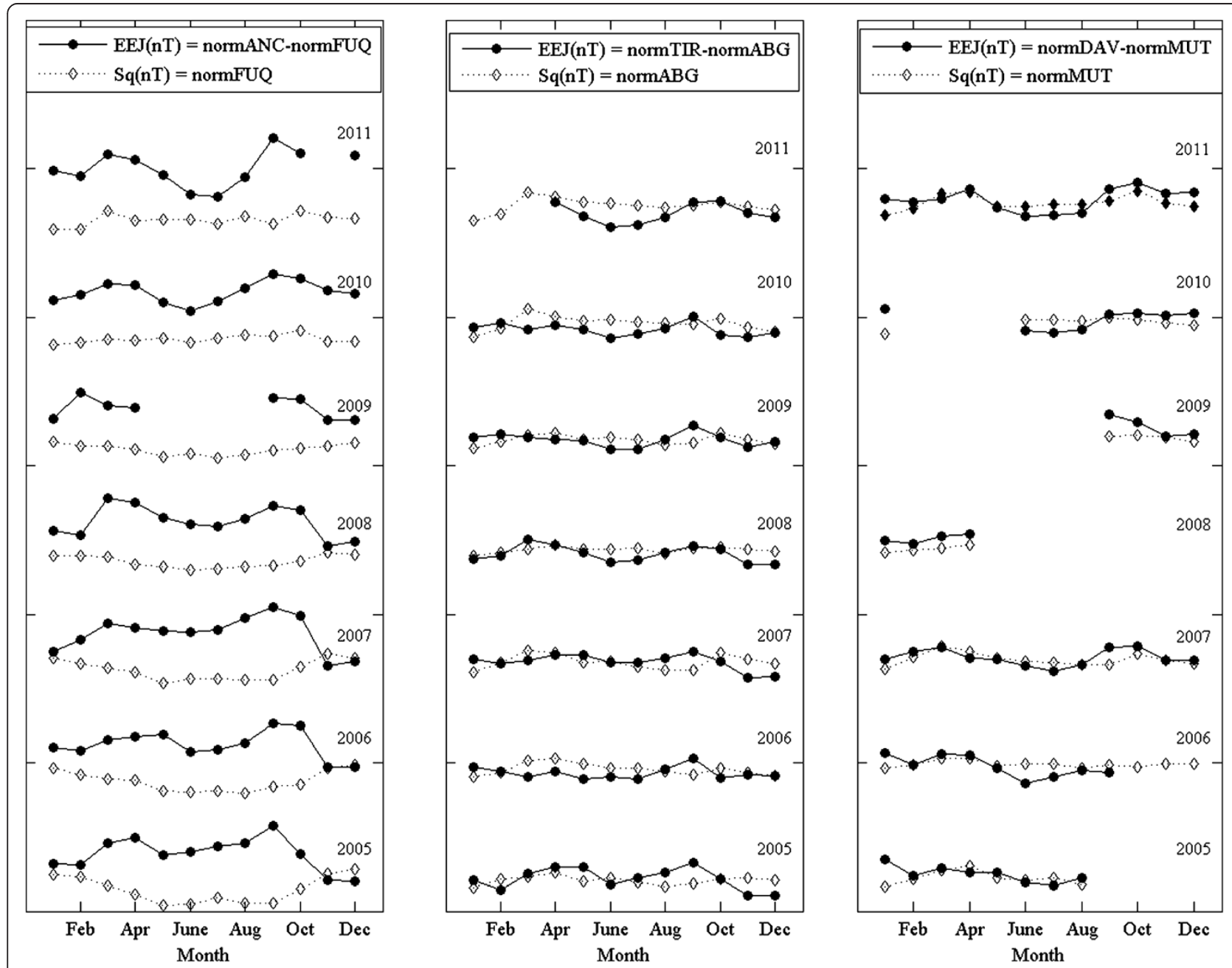

Figure 4 Monthly average of the EEJ and Sq calculated from three station pairs. ANC and FUQ at South America, TIR and ABG at India, and DAV and MUT at Southeast Asia. 


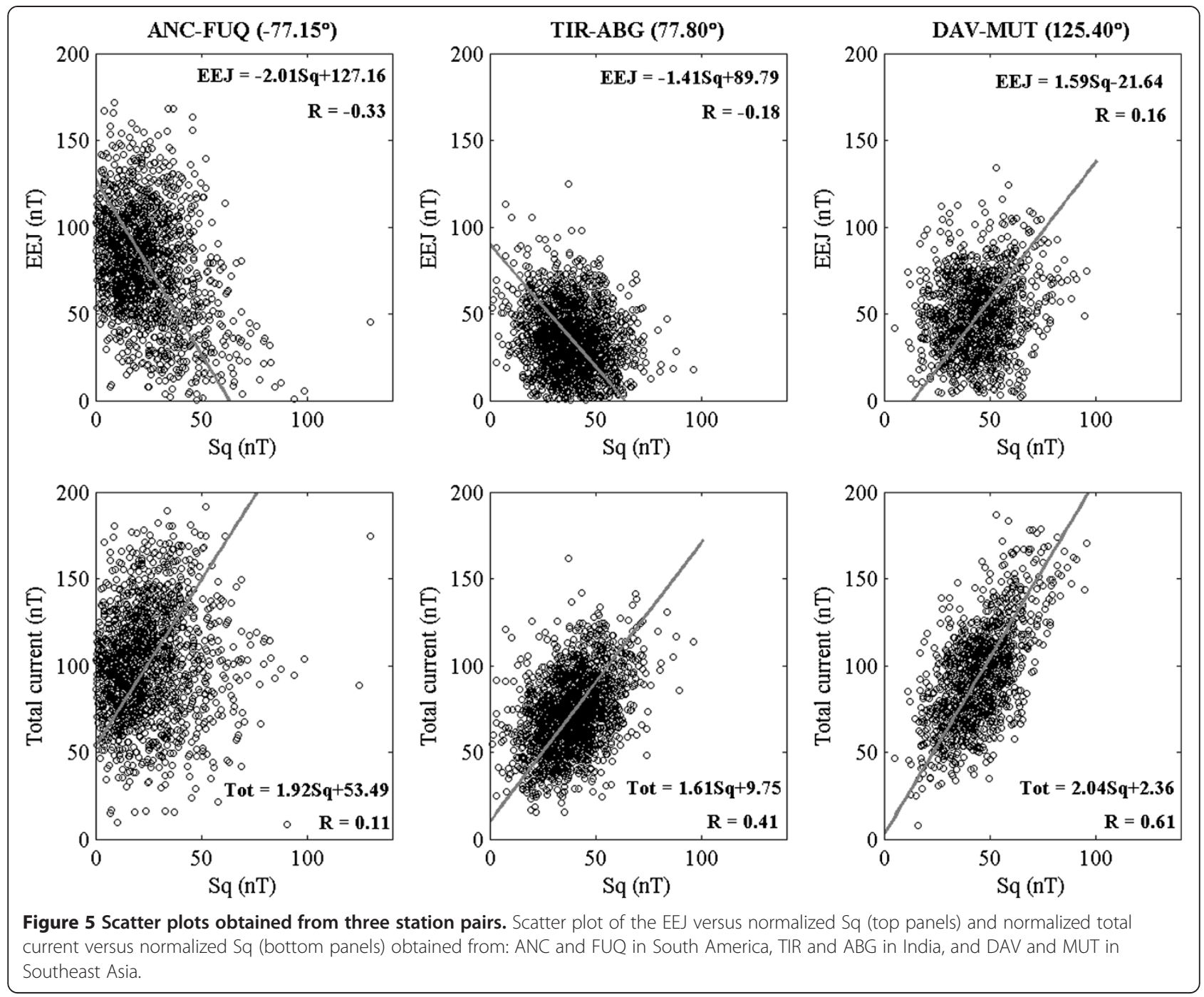

Asian sector but negative in the South American and Indian sectors.

We also examined the relation between the total current and $\mathrm{Sq}$ as illustrated in the bottom panels of Figure 5. As expected from the definition of the total current itself, this current showed a positive linear relation (slope) with Sq for all longitude sectors. The correlation between the total current and Sq was found to be higher than the correlation between the EEJ and Sq in both the Indian and Southeast
Asian sectors, and the $R$ value for the total current and Sq relation was more than 0.5 in the Southeast Asian sector. The $t$-test results showed that both the $\beta$ and $R$ values obtained were significant, and the results are shown in Table 2. These correlation coefficients are consistent with the fact that the Sq component was more significant in the total current for both the Southeast Asian and Indian sectors compared to the South American sector (see Figure 4). Figure 5 thus demonstrates how the definition of EEJ

Table $2 t$-test analysis, $t(d f)=t$, and $p<0.05$ or $p>0.05$ results for both the slope, $\beta$, and correlation coefficient, $R$, where $d f$ is the degree of freedom, $p$ is the $p$-value, $t$ is the t-value

\begin{tabular}{lllll}
\hline & & \multicolumn{2}{l}{-test; $\mathbf{t}(\boldsymbol{d} \boldsymbol{f}) \mathbf{t}, \boldsymbol{p}<\mathbf{0 . 0 5}$ or $\boldsymbol{p}>\mathbf{0 . 0 5}$} & \\
\cline { 3 - 5 } & & South America & India & Southeast Asia \\
\hline EEJ-Sq & $\boldsymbol{\beta}$ & $\mathrm{t}(1508)=-1.2985 \times 10^{3}, p<0.05$ & $\mathrm{t}(1675)=-1.3122 \times 10^{3}, p<0.05$ & $\mathrm{t}(1154)=0.8900 \times 10^{3}, p<0.05$ \\
& $\boldsymbol{R}$ & $\mathrm{t}(1508)=-13.332, p<0.05$ & $\mathrm{t}(1675)=-7.6737, p<0.05$ & $\mathrm{t}(1154)=5.4390, p<0.05$ \\
Total current-Sq & $\boldsymbol{\beta}$ & $\mathrm{t}(1537)=1.1513 \times 10^{3}, p<0.05$ & $\mathrm{t}(1746)=1.6122 \times 10^{3}, p<0.05$ & $\mathrm{t}(1166)=1.3268 \times 10^{3}, p<0.05$ \\
& $\boldsymbol{R}$ & $\mathrm{t}(1537)=4.2502, p<0.05$ & $\mathrm{t}(1746)=18.9416, p<0.05$ & $\mathrm{t}(1166)=26.5052, p<0.05$ \\
\hline
\end{tabular}


affects the conclusion drawn for the EEJ-Sq relationship. In the rest of this paper, we use the EEJ defined by the twostation method for further investigation.

The top row of Figure 5 shows the positive slope and correlation in the Southeast Asian sector, which was opposite of that in other sectors. We noticed that the station pairs we used in the South American and Indian sectors are located north of the dip equator while in Southeast Asia, DAV (dip equator station) is located in the south. We performed the analysis using different station pairs in the Southeast Asian sector along the $210^{\circ}$ chain to investigate whether this northern $(\mathrm{N})$-southern (S) hemisphere (by referring to dip equator) configuration affects the results obtained. The location of these stations is shown in the map on the left panel of Figure 6. A similar regression analysis was performed by using $\mathrm{S}$ $\mathrm{N}, \mathrm{N}-\mathrm{N}, \mathrm{S}-\mathrm{S}$, and N-S station pairs, and these results are shown in the same figure. We can see that although there is some difference in the $\beta$ and $R$, the sign remains positive in all cases and is independent of the hemispheric configuration. We therefore conclude that the EEJ-Sq relationship in the Southeast Asian sector is indeed different from those in the South American and Indian sectors.

We also checked to see if the EEJ-Sq relationship was dependent on the solar activity level by analyzing each year's data from 2005 to 2011 as presented in Figures 7, 8, and 9 for the South American, Indian, and Southeast Asian sectors, respectively. In each figure, we present scatter plots of EEJ versus Sq for each year followed by a plot showing the $P$ parameter, $R$, and slope values. The yearly average $P=0.5(F 10.7+<F 10.7>)$ parameter represents the solar activity level (Richards et al. 1994). The period used in this study was dominated by low solar activity; the lowest $\bar{P}$ value was 68.82 (in 2008) and the highest $\bar{P}$ was 113.84 (in 2011, inclining phase of the solar cycle). Note that we also include a scatter plot for the whole data period in the last panel of each figure, and these are the same as the one that appears in Figure 5. Results show that $R$ values were small for all years; hence, these data confirm that the EEJ and Sq at the dip equator are only weakly correlated to each other regardless of the solar activity level. Again, one can see that the $R$ and slope in the South American and Indian sectors are negative in contrast to the positive values in Southeast Asia. However, we are not sure about the exception in the year 2010 in the Southeast Asian sector as the result might not be significant because of the big data gap for the first six months.

\section{Discussion}

In this paper, with the use of long data set during 2005 to 2011, we reexamined the EEJ-Sq relationship by using appropriate station pairs and a normalization approach. The results obtained revealed a weak correlation between the EEJ and Sq at the dip equator in all three sectors, which included South America, India, and Southeast Asia.

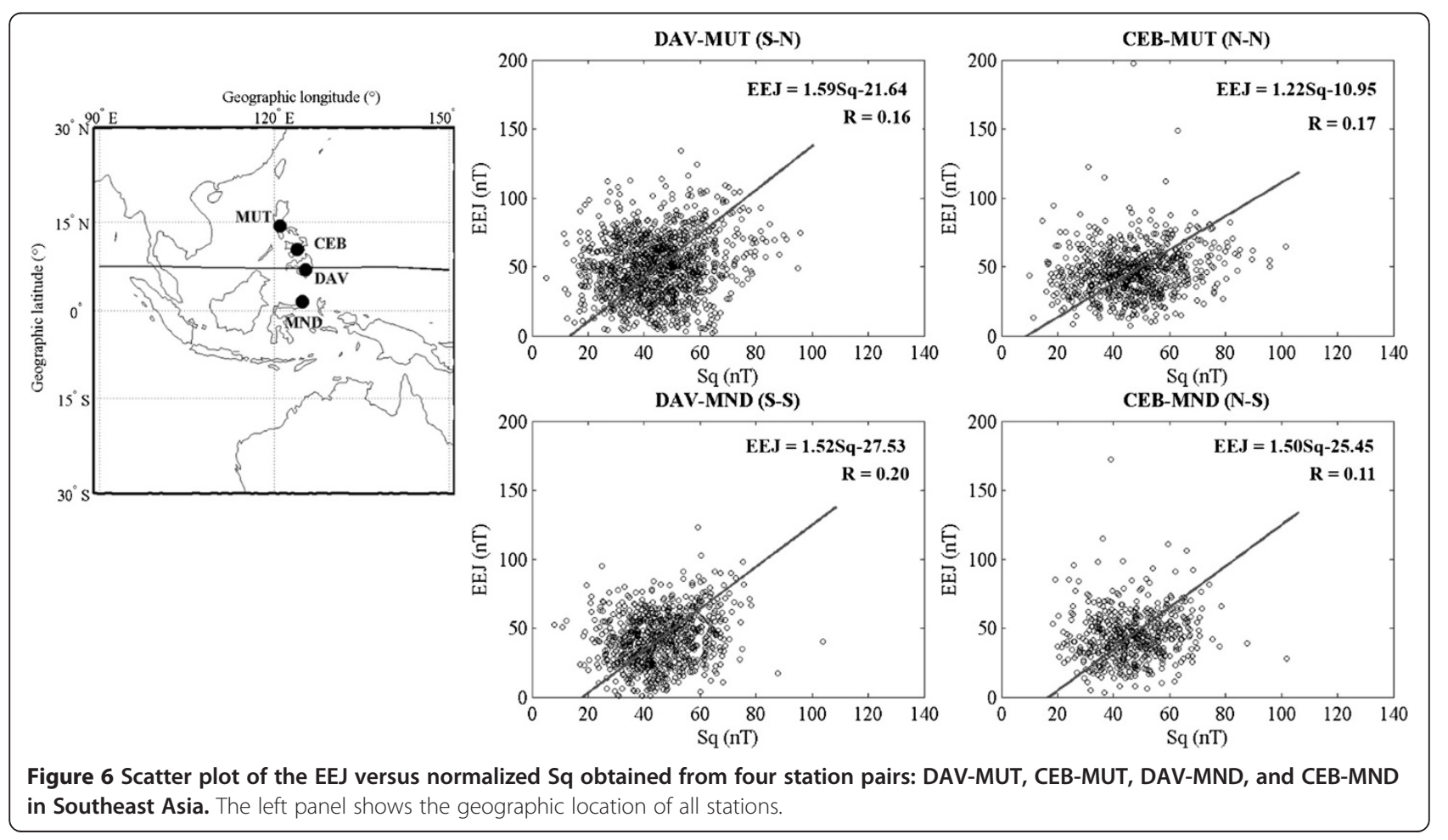




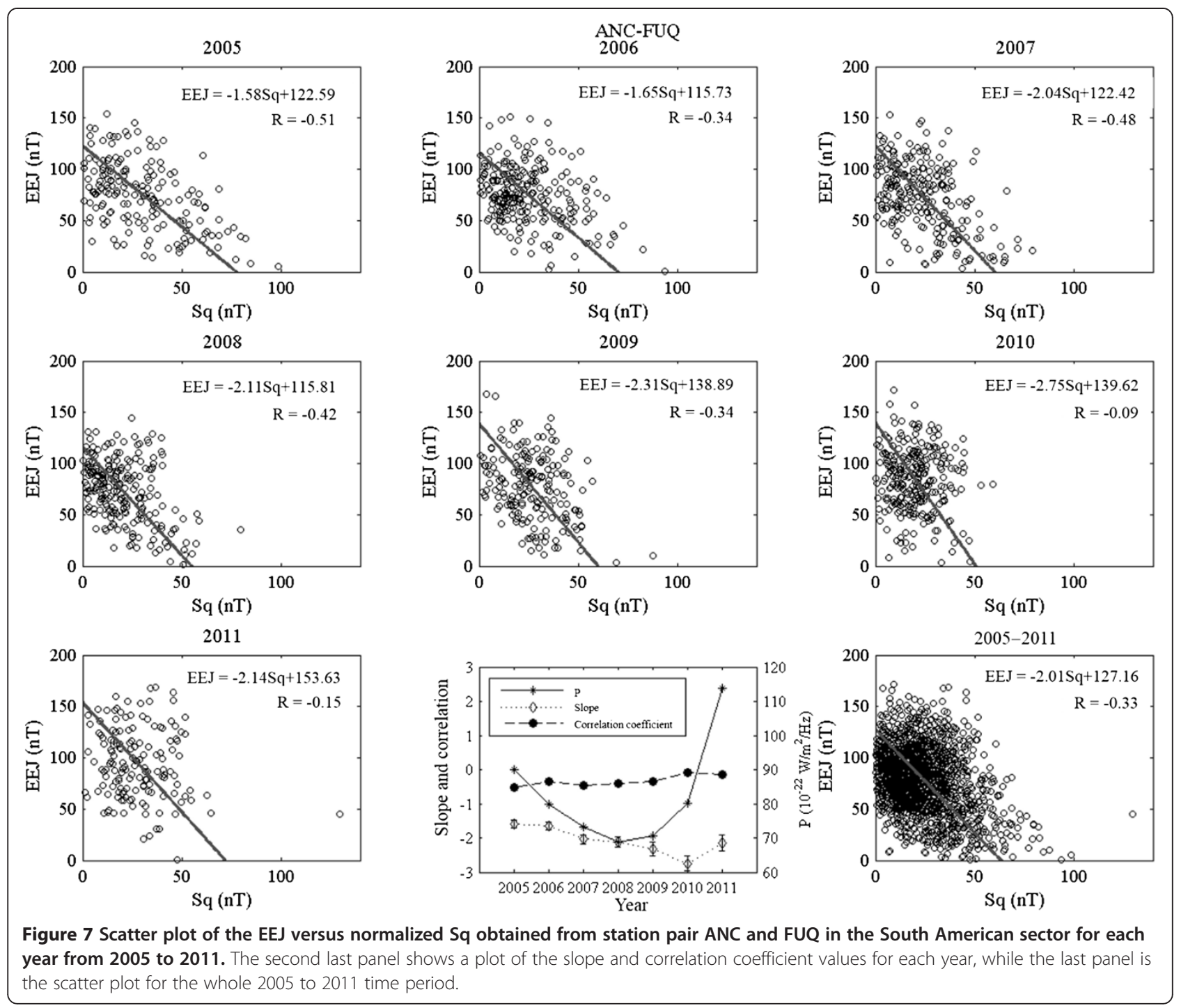

We also found longitudinal dependence in this EEJ-Sq relationship as the relationship in the Southeast Asian sector was different from that in the South American and Indian sectors.

Some previous studies have also reported a weak correlation between the EEJ and Sq. Okeke and Hamano (2000) performed an analysis using data from three dip equator stations located in the South American $\left(-75.2^{\circ}\right)$ and Pacific sectors $\left(-157.5^{\circ}\right.$ and $\left.158.33^{\circ}\right)$. They found small correlation coefficient values between the EEJ and $\mathrm{Sq}$ when the calculations were performed during five quiet days of each month in 1998. Their results are in agreement with work of Okeke et al. (1998), which used data in the Indian sector during the quiet year of 1986. Conversely, a study by Ogbuehi et al. (1967) showed that the correlation coefficient between EEJ and Sq reached -0.6 during the December solstice in 1958. By using the different northern-southern station configurations with the dip equator station located in the western Pacific Ocean, they concluded that the EEJ tends to be negatively correlated with Sq currents measured from stations equatorward of the global Sq current focus. The different results obtained are due to the large longitude separation of the station pairs used in their study, which was quite significant; the separation was about $30^{\circ}$, as the north and south off-dip equator stations were located in Vietnam and Papua New Guinea, respectively. Furthermore, the latitude separations of off-equator stations were remarkable and amounted to $15^{\circ}$ and $17^{\circ}$ for the north and south stations, respectively, and these certainly affected the calculated EEJ current. In general, the longitude and latitude separations of ground stations used in all previous studies were quite big and therefore their results are not conclusive. The new technique applied in this study allowed us to overcome these uncertainties and therefore provides more precise results. 


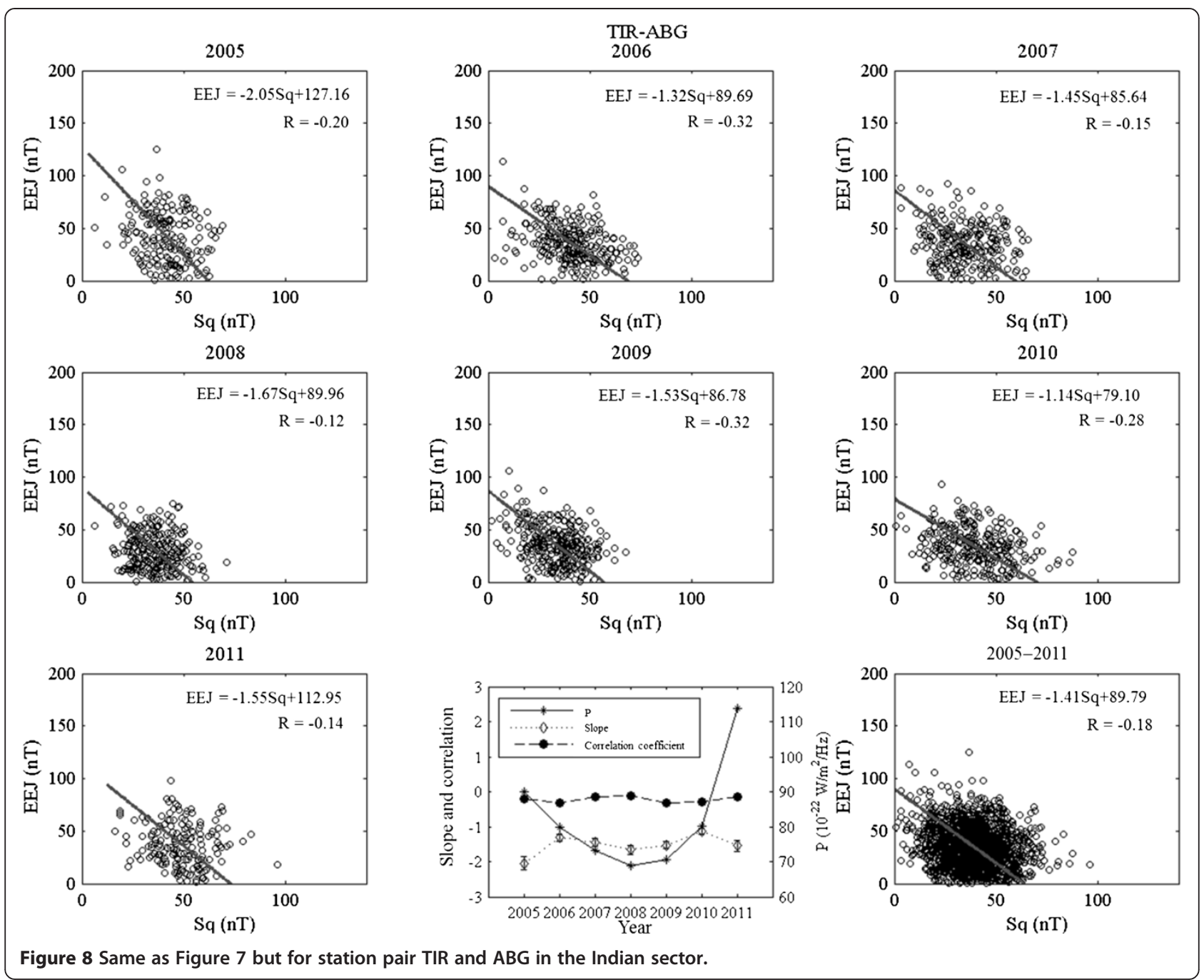

Other previous studies that reported high correlations between EEJ and Sq are Kane (1971) and Yamazaki et al. (2010). However, it should be noted that both of these studies used the total current instead of the EEJ defined by the two-station method, thus their conclusion is essentially about the total current-Sq relationship. Kane (1971) reported a high positive correlation between the total current and Sq during equinoxes and winter using Indian data from quiet days in 1964. Yamazaki et al. (2010) also reported a high positive correlation in the Southeast Asian sector using quiet day data from 1996 to 2005. The results from these two studies are consistent with our results on the total current-Sq relationship shown in the lower row of Figure 5. However, we have also shown how different the EEJ-Sq relationship is from the total current-Sq relationship, with the latter having a generally much higher correlation. The fact that the correlation value between two time series, $x_{1}$ and $x_{2}$, is usually different from that between $x_{1}$ and $x_{1}+x_{2}$ can be used to explain the conflict encountered by the previous researchers in this area. Therefore, it is apparent that the definition of the EEJ significantly affects the conclusion regarding the 'EEJ-Sq' relation. We have adopted the EEJ obtained by the use of the two-station method for our study.

There are several factors that might contribute to the weak correlation between the EEJ and Sq. Rocket measurements by Onwumechili (1992b) showed that the EEJ and $\mathrm{Sq}$ at the dip equator flow at different altitudes where the effective conductivities, electric fields, and winds are different. This suggests that Sq and EEJ are driven by different factors, which could naturally result in a weak correlation between the two. Fang et al. (2008) has demonstrated using a Thermosphere Ionosphere Mesosphere Electrodynamic General Circulation Model (TIME-GCM) simulation that local wind could significantly affect the EEJ. We also know that Sq is affected by large-scale global wind, while EEJ is affected by both global and local wind. At longer time scales (seasonal and solar cycles), the local effect averages out and leads 


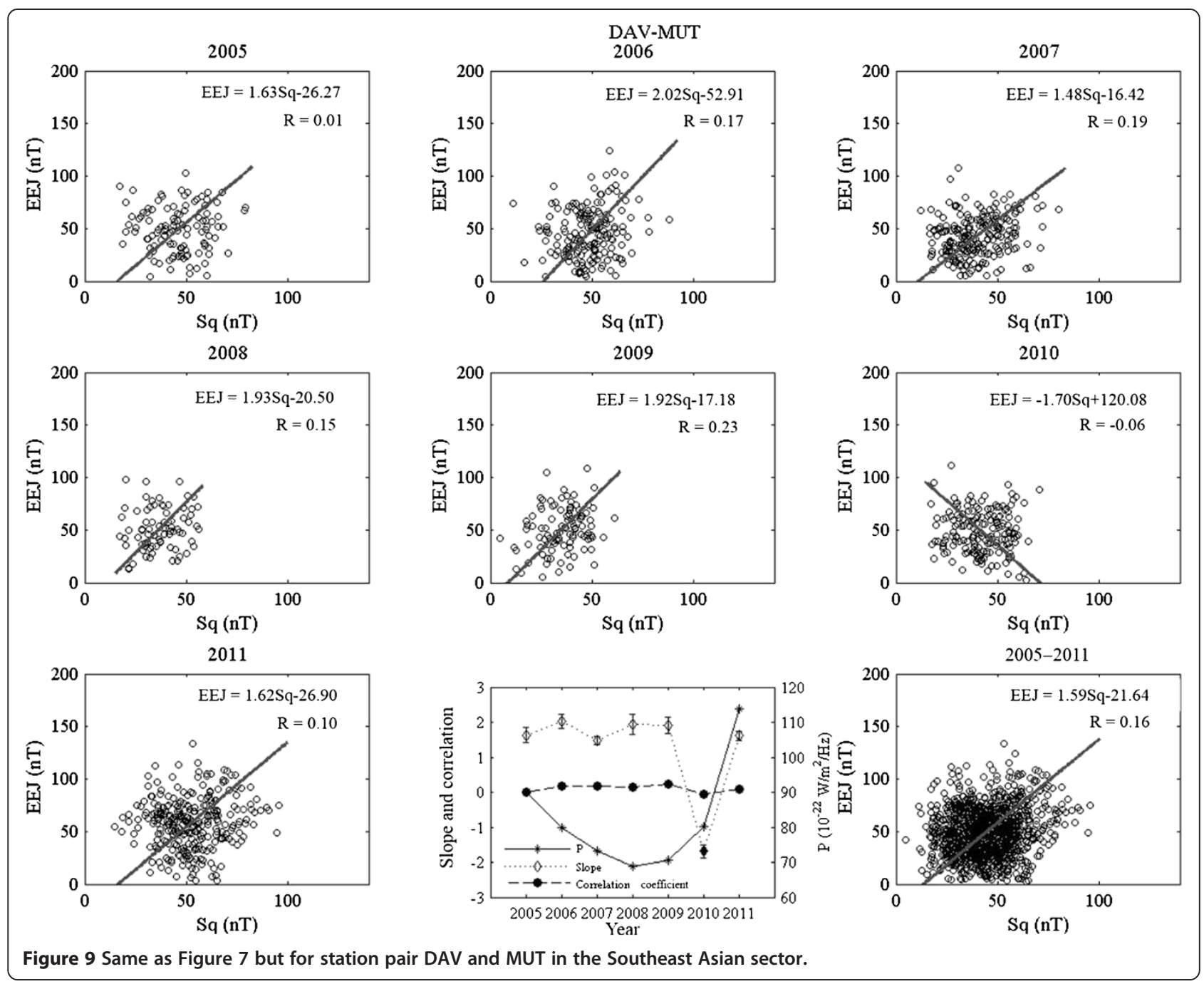

to a similar trend between Sq and EEJ as can be seen in Figure 4. But at shorter time scales, local wind could significantly contribute to the EEJ and lead to a weak correlation between EEJ and Sq. Therefore, the weak correlation obtained in our study implies that the local wind contribution to the EEJ was large. Furthermore, since our analysis used daily values, the weak correlation also implies that day-to-day variability in Sq and EEJ is largely uncorrelated. In addition, some studies have suggested that the EEJ has its own circuit whose return paths and intensity variations are different from the global Sq current (Ogbuehi et al. 1967; Onwumechili, 1992b). This could further contribute to the weak correlation observed at the dip equator.

This study has shown that the EEJ-Sq relationship varies with longitude. In particular, the Southeast Asian sector shows a positive weak correlation, which is opposite to that in the South American and Indian sectors. Since the declination angle in the Southeast Asian sector is similar to that in the Indian sector, it cannot be the cause for the difference. Thus, the difference is likely caused by the wind. The archipelagic state of Southeast Asia causes a warm pool there, which drives intense deep convection activity. This consequently generates excessively strong atmospheric waves (Tsuda and Hocke, 2004), some of which can propagate upward to the dynamo regions to disturb the neutral wind there and hence the electric field and currents. This meteorological aspect may significantly contribute to the unique EEJ-Sq relationship in this sector. Model simulations should be carried out to confirm these findings. Further studies using data from other longitude sectors such as the African sector are also necessary (El Hawary et al. 2012).

\section{Conclusion}

In this paper, we have examined the EEJ-Sq relationship at the dip equator in three longitude sectors including the South American, Indian, and Southeast Asian sectors for geomagnetically quiet days $(K p \leq 3)$ during the years 2005 to 2011. The noontime EEJ and Sq current intensities 
were derived for each day with consideration of latitudinal variation of both currents. The main results of this study are summarized below.

1. Weak correlations between the EEJ and Sq at the dip equator were obtained with a positive value in the Southeast Asian sector and negative values in the South American and Indian sectors.

2. These relations were independent of the hemispheric configuration of stations used to calculate them and also showed little change during low and moderate solar activity levels.

3. These results demonstrate that the Southeast Asian sector is indeed different from the Indian and South American sectors, which is indicative of unique physical processes particularly related to the electro-dynamo. This aspect should be explored in future studies.

4. Finally, we suggest that when studying this type of relationship, one needs to isolate the global Sq contribution from the total current at the dip equator to obtain the EEJ, as we have shown how different the results can be when using the total current.

\section{Competing interests}

The authors declare that they have no competing interests.

\section{Authors' contributions}

NSAH has analyzed the data, carried out the studies, performed the statistical analysis, participated in the sequence alignment, and drafted the manuscript. $\mathrm{HL}$ participated in the sequence alignment and drafted and revised the manuscript and has given final approval of the version to be published. TU participated in the interpretation of data and revised the manuscript. KY, BV, $A Y$, and JAS have contributed in the acquisition of data and revised the manuscript. All authors read and approved the final manuscript.

\section{Acknowledgements}

We thank all the members of the MAGDAS project for their cooperation and contribution to this study. Financial support was provided by the Japan Society for the Promotion of Science (JSPS) (No. 25800274) and a Shisedo Science Grant (2013). We are also grateful to JSPS for supporting the Overseas Scientific Survey (Nos. 15253005 and 18253005) and publications of the scientific research results (Nos. 188068, 198055, 208043). We acknowledge the National Oceanic and Atmospheric Administration (NOAA) for providing Kp index data, Goddard Space Flight Center/Space Physics Data Facility (GSFC/SPDF) OMNIWeb at http://omniweb.gsfc.nasa.gov for providing F10.7 data, and the National Geophysical Data Center (NGDC) for the estimated values of the magnetic inclination component.

\footnotetext{
Author details

'Department of Earth and Planetary Sciences, Graduate School of Sciences, 33 Kyushu 4 University, 6-10-1 Hakozaki, Higashi-ku, Fukuoka 812-8581, Japan. ${ }^{2}$ School of Applied Physics, Faculty of Science and Technology, Universiti Kebangsaan Malaysia, 43600 UKM, Bangi, Selangor, Malaysia. ${ }^{3}$ International Center for Space Weather Science and Education (ICSWSE), Kyushu University 53, 6-10-1 Hakozaki, Higashi-ku, Fukuoka 812-8581, Japan. ${ }^{4}$ Indian Institute of Geomagnetism, Navi Mumbai 410 218Maharashtra, India. ${ }^{5} \mathrm{~J}$. Geomagnetic Avendaño, S66 Observatorio Fuquene, Geographic Institute Agustin Codazzi, Bogotá, Colombia.
}

\section{References}

El Hawary R, Yumoto K, Yamazaki Y, Mahrous A, Ghamry E, Meloni A, Badi K, Kianji G, Uiso CBS, Mwiinga N, Joao L, Affluo T, Sutcliffe PR, Mengistu G, Baki P, Abe S, Ikeda A, Fujimoto A, Tokunaga T (2012) Annual and semi-annual Sq variations at $96^{\circ}$ MM MAGDAS I and II stations in Africa. Earth Planets Space 64:425-432

Fang TW, Richmond AD, Liu JY, Maute A (2008) Wind dynamo effects on ground magnetic perturbations and vertical drifts. J Geophys Res 113, A11313, doi:10.1029/2008JA013513

Forbes JM (1981) The equatorial electrojet. Rev Geophys Space Phys 19:469-504

Hamid NSA, Liu H, Uozumi T, Yumoto K (2013) Equatorial electrojet dependence on solar activity in the Southeast Asia sector, Antarct. Record 57(3):329-337

Hirono M (1950) On the influence of the hall current to the electrical conductivity of the ionosphere. I J Geomagn Geoelectr 2:1

Hirono M (1952) A theory of diurnal magnetic variations in equatorial regions and conductivity of the ionosphere $E$ region. J Geomagn Geoelectr 4:7

Kane RP (1971) Relationship between $H$ ranges at equatorial and middle latitudes. J Atmos Solar-Terr Phys 33:319-327

Mann RJ, Schlapp DM (1988) The equatorial electrojet and the day-to-day variability of Sq. J Atmos Solar-Terr Phys 50(1):57-62

Manoj C, Lühr H, Maus S, Nagarajan N (2006) Evidence for short spatial correlation lengths of the noontime equatorial electrojet inferred from a comparison of satellite and ground magnetic data. J Geophys Res 111, A11312, doi:10.1029/2006JA011855

Ogbuehi PO, Onwumechilli A, Ifedili SO (1967) The equatorial electrojet and the world-wide Sq currents. J Atmos Solar-Terr Phys 29:149-160

Okeke FN, Hamano Y (2000) The ionospheric dynamo and magnetic variations across latitudes. Irish Astronomic J 27(2):141-144

Okeke FN, Onwumechili CA, Rabiu BA (1998) Day-to-day variability of geomagnetic hourly amplitudes at low latitudes. Geophys J Int 134:484-500

Onwumechili CA (1992a) Study of the return current of the equatorial electrojet. J Geomagn Geoelectr 44:1-42

Onwumechili CA (1992b) A study of rocket measurements of ionospheric currents. -IV. Ionospheric currents in the transition zone and the overview of the study. Geophys J Int 108:660-672

Onwumechili CA (1997) The Equatorial Electrojet. Gordon and Breach Science Publishers, The Netherlands, Amsterdam

Prölss GW (2004) Physics of the Earth's Space Environment, An Introduction. Springer, Germany

Rastogi RG, Chandra H, Yumoto K (2013) Unique examples of solar flare effects in geomagnetic $\mathrm{H}$ field during partial counter electrojet along CPMN longitude sector. Earth Planets Space 65:1027-1040

Richards PG, Fennelly JA, Torr DG (1994) EUVAC: a solar EUV flux model for aeronomic calculations. J Geophys Res 99(A5):8981-8992

Rigoti A, Chamalaun FH, Trivedi NB, Padilha AL (1999) Characteristics of the equatorial electrojet determined from an array of magnetometers in N-NE Brazil. Earth Planets Space 51:115-128

Sabaka TJ, Olsen N, Purucker ME (2004) Extending comprehensive models of the Earth's magnetic field with Ørsted and CHAMP data. Geophys J Int 159:521-547

Stening RJ (1995) What drives the equatorial electrojet? J Atmos Solar-Terr Phys $57: 1117-1128$

Tsuda T, Hocke K (2004) Application of GPS occultation for studies of atmospheric waves in the middle atmosphere and ionosphere. J Meteor Soc Japan 82:419-426

Uozumi T, Yumoto K, Kitamura K, Abe S, Kakinami Y, Shinohara M, Yoshikawa A, Kawano H, Ueno T, Tokunaga T, McNamara D, Ishituka JK, Dutra SLG, Damtie B, Vafi D, Obrou O, Rabiu AB, Adimula IA, Othman M, Fairos M, Otadoy RES, MAGDAS Group (2008) A new index to monitor temporal and long-term variations of the equatorial electrojet by MAGDAS/CPMN real-time data: EE-Index. Earth Planets Space 58:1-11

Yamazaki Y, Yumoto K, Uozumi T, Abe S, Cardinal MG, McNamara D, Marshall R, Shevtsov BM, Solovyev SI (2010) Reexamination of the Sq-EEJ relationship based on extended magnetometer networks in the east Asian region. J Geophys Res 115, A09319, doi:10.1029/2010JA015339

Yumoto K, the MAGDAS Group (2007) Space weather activities at SERC for IHY: MAGDAS. Bull Astronomic Soc India 35:511-522

\section{doi:10.1186/s40623-014-0146-2}

Cite this article as: Hamid et al:: Relationship between the equatorial electrojet and global Sq currents at the dip equator region. Earth, Planets and Space 2014 66:146. 